\title{
ANTIASTHMATIC ACTIVITY OF THE ETHANOL EXTRACT OF LEAVES OF WRIGHTIA TINCTORIA
}

\author{
ZASEEM KHAN*, IMTIYAZ ANSARI \\ Department of Pharmacology, Oriental College of Pharmacy, Sanpada, Navi Mumbai - 400 705, Maharashtra, India. \\ Email: zaseem.pharmacy@gmail.com
}

Received: 22 March 2018, Revised and Accepted: 16 May 2018

\begin{abstract}
Objective: The objective of this study was to evaluate the antiasthmatic activity of ethanolic extract of Wrightia tinctoria leaves in albino wistar rats.

Methods: The plant extract was taken by soxhlet apparatus with $90 \%$ ethanol. Two methods are carried out such as milk-induced leukocytosis and ovalbumin-induced leukocytosis; ( $4 \mathrm{ml} / \mathrm{kg}$ ) milk induced as intoxicant given by subcutaneous, ( $4 \mathrm{ml} / \mathrm{kg}$ ) ovalbumin given by intraperitoneal injection, and standard drug as dexamethasone (50 mg/kg) given for both activity and drug extract for all three test groups (low, medium, and high) blood collected from the retro-orbital plexus and count the leukocytes before and after $24 \mathrm{~h}$ after drug administration.
\end{abstract}

Result: Test 1 , Test 2 , and Test 3 groups were found to significantly $\left({ }^{* *} \mathrm{p}<0.01\right)$ decrease ambulation counts as compared to milk and ovalbumin control group. The treatment group was founded to significantly ( $\left.{ }^{* *} \mathrm{P}<0.01\right)$ milk and ovalbumin control group increases ambulation count as compared to all test groups and standard groups.

Conclusion: In this study, we conclude that an ethanolic extract of the leaves of $W$. tinctoria possesses a significant antiasthmatic property, which is probably mediated through inhibition of histamine. The activity shown by ethanolic extract of $W$. tinctoria was found to be dose dependent.

Keywords: Antiasthmatic, Milk, Ovalbumin, Wrightia tinctoria, Leukocytosis.

(C) 2018 The Authors. Published by Innovare Academic Sciences Pvt Ltd. This is an open access article under the CC BY license (http://creativecommons. org/licenses/by/4. 0/) DOI: http://dx.doi.org/10.22159/ajpcr.2018.v11i9.26151

\section{INTRODUCTION}

Asthma is a complex inflammatory disease causing airway narrowing, and it is associated with changes in the level of mast cell, lymphocytes, cytokines, and other inflammatory cell product [1]. Asthma affects about 300 million people worldwide, and it has been estimated that a further 100 million will be affected by 2025 [2]. Wrightia tinctoria, Pala indigo plant or dyers's oleander, is a flowering plant species in the genus Wrightia belong to family: Apocynaceae. In Hindi: कपार Kapar, in Tamil: palali, in Marathi: Kala Kuda, in Malayalam: Aiyapalai, Neelappala, in Kannada: Ajmara. Found in India, Southeast Asia, and Australia, and is also a native of Burma. It is found in dry and moist regions in its distribution. Various parts of the plant have medicinal properties [3]. It contains triterpenoid as well as cycloartenone and cycloelucalenol. It possesses different pharmacological activity, including anti-ulcer, anthelmintic, anti-inflammatory, antimicrobial, and antidiabetic [4-7]. The leaves contain triterpenoid constitutes as well as cycloartenone, cycloeucalenol, $\beta$-amyrin, and $\beta$-sitosterol. Triterpenoids contain lupeol administration of lupeol caused the reduction of cellularity and eosinophils in the bronchoalveolar lavage fluid. The leaves of W. tinctoria also contain flavonoids such as luteolin and apigenin which possess potential antiasthmatic activity. Luteolin is a kind of a plantderived natural compound with an immunomodulatory effect, and it is possible that luteolin could be a useful therapeutic agent against allergic asthma and rhinitis [8,9] (Fig. 1).

\section{METHODS}

\section{Preparation of plant extracts}

The collected leaves of $W$. tinctoria were washed and sundried for 6 days, and the dried leaves were grinded to make a smooth powder and sieved through the mesh for fine powder. Powder was stored in a cool and dry place until extraction. Extraction was done using ethanol $(90 \% \mathrm{v} / \mathrm{v})$ in a Soxhlet apparatus at $60^{\circ} \mathrm{C}$. The solvent was completely evaporated in the hot air oven. The extract was stored in airtight container at $4^{\circ} \mathrm{C}$ until use. The yield was observed to be $28 \% \mathrm{w} / \mathrm{w}$.

\begin{abstract}
Animals
Animals required for the research work were approved by the Oriental College of Pharmacy, Sanpada Institutional Animal Ethics Committee (IAEC) Proposal No. OCP/IAEC/2017-2018/01. Animals procured were male albino wistar rats (200 to $2500 \mathrm{GM}$ )/were obtained from Bharat Serums and Vaccines Limited (CPCSEA REG NO. 103/PO/NRcRcRcBiBt/ SL/CPCSEA dated 27/04/2017).The animals were housed in well ventilated, air conditional animal house at a constant temperature of $23^{\circ} \mathrm{C} \pm 2^{\circ} \mathrm{C}$, with the relative humidity of $55-60 \%$. The animals were housed in spacious polypropylene cages with paddy husk as bedding material. The animals were maintained on a standard pellet diet and purified water. The animals were provided with food and acclimatize for a period of 7 days.
\end{abstract}

\section{Induction of milk and ova-albumin}

After overnight fasting, before $30 \mathrm{~min}$ the drug was administered, over $30 \mathrm{~min}$ the milk was induced by subcutaneous injection $(4 \mathrm{ml} / \mathrm{kg})$. The control group received normal saline as alone. After $24 \mathrm{~h}$, the leukocytes count before and after $24 \mathrm{~h}$ of drug administration. After completion 10 days of washing period, the ovalbumin was induced by intraperitoneal injection ( $0.2 \mathrm{ml}$ per rat), on day $7,(0,7$, and 14$)$ after 8 days, the leukocyte count was done for increasing leukocytosis level in asthma.

\section{Experimental design}

A total of 36 rats were used in the present investigation. The animals were randomly divided into six groups of six rats in each group.

\section{Milk-induced leukocytosis}

Group 1: Normal saline (1 ml $/ \mathrm{kg}$ )

Group 2: Milk (intoxicant) $(4 \mathrm{ml} / \mathrm{kg})$ 
Group 3: Dexamethasone (standard) (50 mg/kg)

Group 4: W. tinctoria + Milk (100 mg/kg)

Group 5: W. tinctoria + Milk (150 mg/kg)

Group 6: W. tinctoria + Milk (250 mg/kg)

\section{Ovalbumin-induced leukocytosis}

Group 1: Normal saline $(1 \mathrm{ml} / \mathrm{kg})$

Group 2: Ovalbumin (4 ml $/ \mathrm{kg})$

Group 3: Dexamethasone (standard) $(50 \mathrm{mg} / \mathrm{kg})$

Group 4: W. tinctoria + Ova-albumin $(100 \mathrm{mg} / \mathrm{kg})$

Group 5: W. tinctoria + Ova-albumin $(150 \mathrm{mg} / \mathrm{kg})$

Group 6: W. tinctoria + Ova-albumin $(250 \mathrm{mg} / \mathrm{kg})$

\section{Sample collection}

\section{Milk-induced leukocytosis}

Rats were divided into six groups with six in each group. Blood samples were collected from the retro-orbital plexus. Group 1 served as normal saline, Group 2 received milk subcutaneous. Group 3 received standard as dexamethasone $(50 \mathrm{mg} / \mathrm{kg})$ as intraperitoneal injection, Group 4 to Group 6 was received EEWT in low intermediate and high dose. Except normal, all the groups were injected boiled and cooled milk ( $4 \mathrm{ml} / \mathrm{kg}$, $\mathrm{SC}$.) for $30 \mathrm{~min}$ after treatments. Total leukocyte count was done in each group before administration of the test compound and $24 \mathrm{~h}$ after milk injection. The difference in total leukocytes count before and after 24-h drug administration was calculated [10].

\section{Ovalbumin-induced leukocytosis}

Except normal, all rats are sensitized intraperitoneally (IP) with 0.2 $\mathrm{ml}$ ovalbumin mixed with alum on days 0,7 , and 14 . Group 1 received normal saline, Group 2 received ovalbumin, Group 3 received standard as dexamethasone, and Group 4 to Group 6 received EEWT in lowintermediate high dose. On day 21, except normal all groups were injected ovalbumin (0.2 ml IP) $30 \mathrm{~min}$ after treatment. The rats was exposed to aerosolized $1 \mathrm{ml}$ ovalbumin in $100 \mathrm{ml}$ phosphate buffer solution for $1 \mathrm{~h}$ on day 22 and 24 . On day 24 , after an aerosolized, a total number of leukocytosis counts before and after $24 \mathrm{~h}$ drug administration was calculated [11].

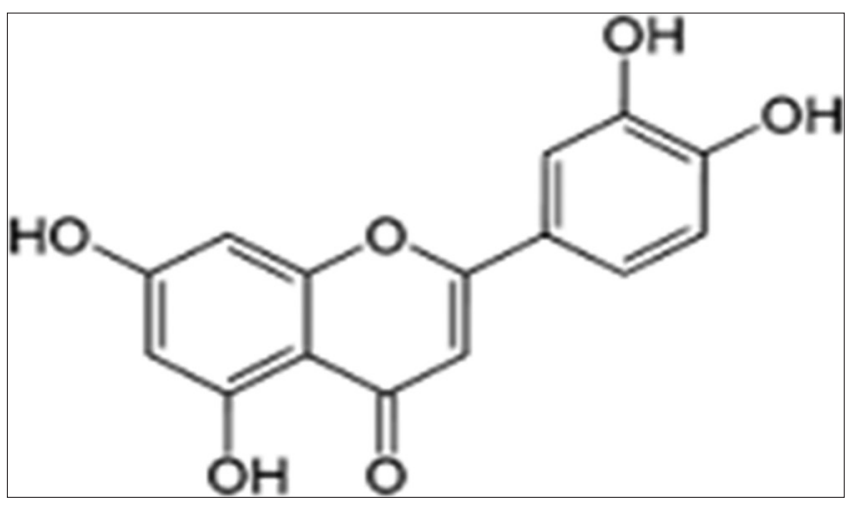

Fig. 1: Luteolin

\section{Statistical analysis}

Data were analyzed with Instat. The result is expressed as the mean \pm standard error of the mean for each group. Statistical differences were evaluated using a one-way analysis of variance followed by Tukey's t-test. Results were considered to be statistically significant at ${ }^{* *} \mathrm{p}<0.01$.

\section{RESULTS AND DISCUSSION}

\section{Milk-induced leukocytosis}

Leukocyte recruited during asthmatic inflammation, release the inflammatory mediators such as cytokines, histamine, and major basic protein which promotes ongoing inflammation. Leukocytes are the cells of the immune system that are involved in protecting the body against both infectious disease and foreign invaders. It has been demonstrated that subcutaneous administration of milk produces a marked and significant increase in leukocyte count after $24 \mathrm{~h}$ of administration. The milk-induced leukocytosis in rat model helps evaluate the antiasthmatic activity (Table 1 and Fig. 2).

\section{Ovalbumin-induced leukocytosis}

It has been demonstrated that intraperitoneal administration of ovalbumin produces a marked and significant increase in leukocyte count after $24 \mathrm{~h}$ of administration. Ovalbumin induced an increase in airway resistance, airway inflammation, and goblet cell hyperplasia. Injected the ovalbumin in rats, the lung tissue was hugely inflamed, and at the longer time points, scar tissue was apparent before injecting ovalbumin the lungs look normal with the reestablishment of intact endothelial lining and the absence of inflammation (Table 2 and Fig. 3).

\section{CONCLUSION}

The antiasthmatic property of $W$. tinctoria in ethanol-induced asthma model is evident from its significant increases in total leukocytes and number of asthma. The preliminary phytochemical analysis of $W$. tinctoria extract showed the presence of triterpenoids, steroids, flavonoids, tannins, and phenolic. The significant increase in the antiasthmatic activity of $W$. tinctoria could be attributed to the presence of flavonoids (luteolin), steroids, tannins, and phenolic compounds. Steroids and other antiasthmatic drugs work by reducing inflammation, swelling, and mucus production in the airways of a person with asthma. As a result, the airways are less inflamed and less likely to react to asthma triggers, allowing people with symptoms of asthma to have better control over their condition. W. tinctoria and may also be useful in the development of new formulations of this plant with more potential therapeutic and good economic value. Further studies to identify the active moieties and elucidation of the mechanism of action are recommended. It has been concluded that the ethanolic extract of $W$. tinctoria showed a dose-dependent activity in ethanol-induced asthma in albino rats. The active constituents can be isolated from W. tinctoriafurther studies on their estimate function can be analyzed.

\section{ACKNOWLEDGMENT}

The authors are thankful to our principal Dr. Mrs. Sudha Rathod, Oriental College of Pharmacy, Sanpada, Navi Mumbai, for providing a

Table 1: Milk-induced leukocytosis

\begin{tabular}{llll}
\hline Treatment & \multicolumn{2}{l}{ Number of leukocytosis (Cu.mm.) } & Difference (mean \pm SEM) \\
\cline { 2 - 4 } & Before (mean \pm SEM) & After (mean \pm SEM) & $320.84 \pm 2.85$ \\
\hline Normal saline & $6279.66 \pm 4.63$ & $6600.5 \pm 1.78$ & $6369.66 \pm 1.31$ \\
(Control) Milk & $6498.5 \pm 4.93$ & $12868.16 \pm 3.62$ & $1230 \pm 0.39^{* *}$ \\
Dexamethasone & $7248.16 \pm 2.28$ & $8478.16 \pm 2.67$ & $5940 \pm 0.16^{* *}$ \\
Test 1+Milk & $5174.5 \pm 2.24$ & $11114.5 \pm 2.40$ & $2999.67 \pm 0.04^{* *}$ \\
Test 2+Milk & $7270.66 \pm 1.78$ & $10270.33 \pm 1.82$ & $2510.17 \pm 1.93^{* *}$ \\
Test 3+Milk & $5828.33 \pm 0.66$ & $8338.5 \pm 2.59$ & \\
\hline
\end{tabular}

All values are expressed in mean \pm SEM of ambulation count no=6. Dexamethasone (STD), test 1 , test 2 , and test 3 group was found to significantly $(* * p<0.01$ ) decrease ambulation counts as compared to the milk control group. Treatment groups were found to significantly $\left({ }^{* *} \mathrm{p}<0.01\right)$. Milk control group increases ambulation count as compared to all test groups and standard group. SEM: Standard error of the mean 


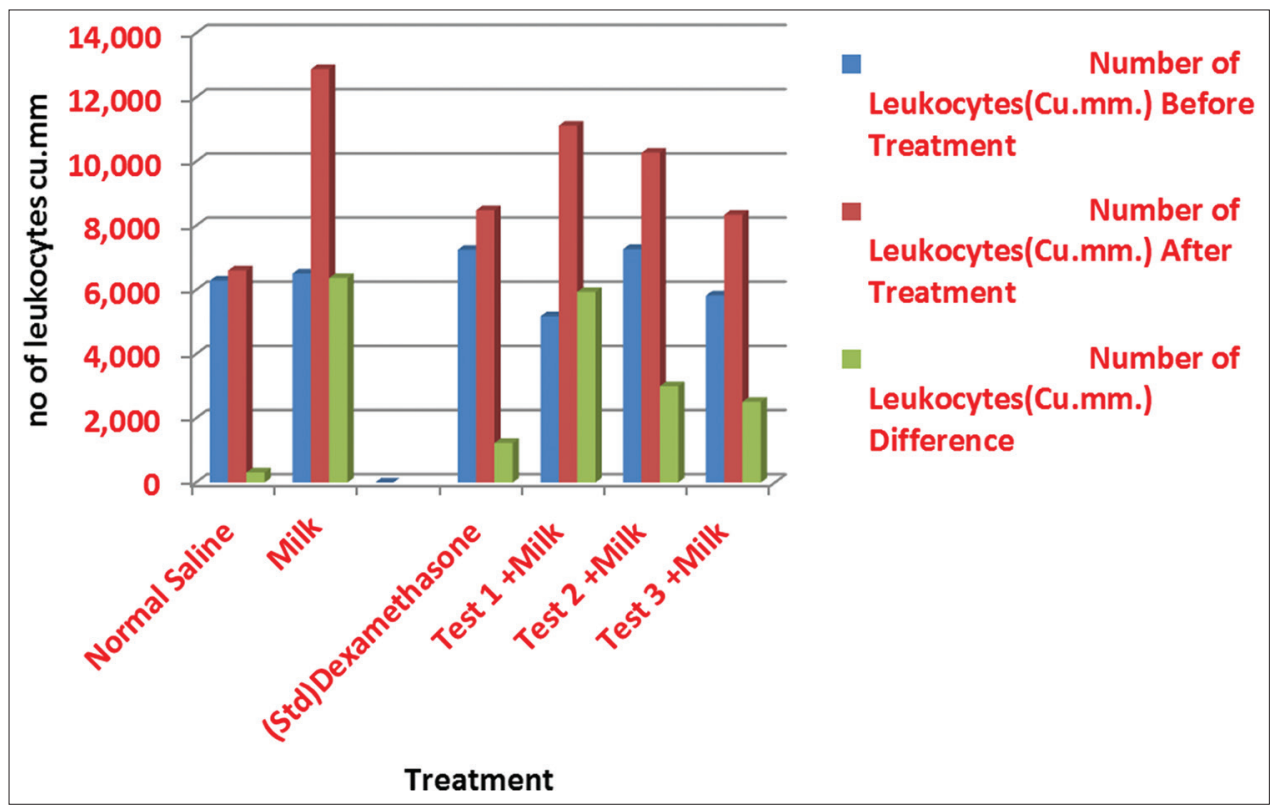

Fig. 2: Milk-induced leukocytosis

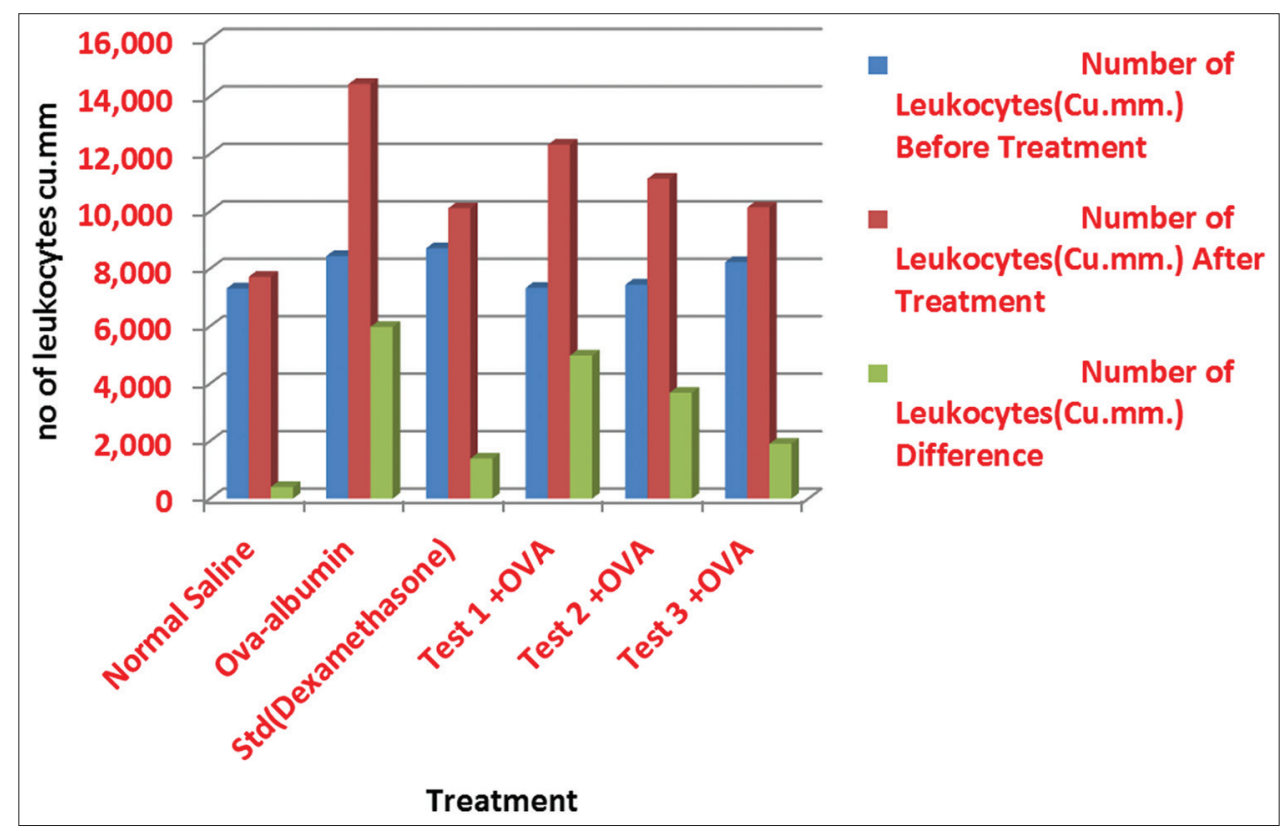

Fig. 3: Ovalbumin-induced leukocytosis

Table 2: Ovalbumin-induced leucocytosis

\begin{tabular}{|c|c|c|c|}
\hline \multirow[t]{2}{*}{ Treatment } & \multicolumn{3}{|c|}{ Number of leukocytosis (Cu.mm.) } \\
\hline & Before (mean \pm SEM) & After (mean \pm SEM) & Difference (mean \pm SEM) \\
\hline Normal saline & $7318.66 \pm 0.91$ & $7716 \pm 2.95$ & $397.34 \pm 2.04$ \\
\hline (Control) ovalbumin & $8445.83 \pm 1.83$ & $14429.16 \pm 1.70$ & $5983.33 \pm 0.13$ \\
\hline Dexamethasone & $8709 \pm 1.21$ & $10107.33 \pm 1.58$ & $1398.33 \pm 0.37^{* *}$ \\
\hline Test 1+OVA & $7339.66 \pm 1.17$ & $12319 \pm 0.89$ & $4979.34 \pm 0.28^{* *}$ \\
\hline Test 2+OVA & $7445.66 \pm 2.27$ & $11138.83 \pm 1.57$ & $3693.17 \pm 0.7^{* *}$ \\
\hline Test 3+OVA & $8225 \pm 2.74$ & $10133.83 \pm 2.16$ & $1908.83 \pm 0.58^{* *}$ \\
\hline
\end{tabular}

All values are expressed in mean \pm SEM of ambulation count no=6. Dexamethasone (STD), Test 1 , Test 2 , and Test 3 group was found to significantly $(* * p<0.01$ ) decrease ambulation counts as compared to ovalbumin control group. The treatment group was founded to significantly ( $* *$ p $<0.01)$. Ovalbumin control group increases ambulation count as compared to all test groups and standard group. SEM: Standard error of the mean 
platform and facility to conduct research work, the author Mr. Zaseem Khan would also like to thank Bharat Seerum and Vaccines Ltd. for providing the animals.

\section{CONFLICTS OF INTERESTS}

The authors declare that there is no conflict of interests regarding the publication of this paper.

\section{AUTHORS CONTRIBUTION}

We declare that this work was done by the authors named in this article and all liabilities pertaining to claims relating to the content of this article will be borne by the authors. Mr. Zaseem Khan collected the data, analyzed the data, all the laboratory work performed, wrote the introduction, and discussion and the material and method part. Mr. Imtiyaz Ansari proofreads the whole manuscript as well as helps in designing and conducting the study.

\section{REFERENCES}

1. Kirtikar KR, Basu BD. Indian Medicinal Plant. $2^{\text {nd }}$ ed. Dehradun: International Book Distributor; 1987. p. 763-7.

2. Masoli M, Fabian D, Holt S, Beasley R. The global burden of asthma: Executive summary of the GINA dissemination committee report. Allergy 2004;59:468-9.

3. Nadkarni KM. Indian Materia Medica. Bombay: Popular Prakashan;
1976. p. 1296.

4. Nagalakshmi HS, Das A, Bhattacharya S. In vitro antimicrobial properties and phytochemical evaluation of mature seed extracts of Wrightia tinctoria R. Br J Pure Appl Microbiol 2012;6:1273-9.

5. Rani MS, Pippalla RS, Mohan GK, Raju AB, Kumar VH. In vitro study of methanolic extracts of Dodonaea viscosa Linn and Wrightia tinctoria $\mathrm{R}$. Br. on glucose uptake by isolated rat hemi-diaphragm. Int J Chem Sci 2012;10:1724-30.

6. Divakar MC, Devi SL. Antiulcer activity of Wrightia tinctoria (Roxb.) R. Br Der Pharm Sin 2011;2:355-60.

7. Dama GY, Tare HL, Gore MS, Deore SR, Bidkar JS. Comparative hemintholytic potential of extracts obtained from Cymbopogon citratus and Wrightia tinctoria leaves. Int J Pharm Biol Sci 2011;2:327.

8. Bhargava KP, Singh N. Anti-stress activity of Ocimum sanctum. Indian J Med Res 1981;73:443-5.

9. Meihau JI, Yang JH, Lee E, Lu Y. Clinical features and the molecular biomarker of olfactory Neuroblastoma. Gyeongsan: College of Pharmacy, Yeungnam University; 2015. p. 712-49.

10. Bhalke RD, Giri MA, Anarthe SJ Pal AC. Antiulcer activity of the ethanol extract of leaves of Sesbania grandiflora (Linn.). Int J Pharm Pharm Sci 2010;2:206-8.

11. Deasai SK, Desai SM, Navdeep S, Arya P, Pooja T. Antistress activity of Boerhaavia diffusa root extract and a polyherbal formulation containing Boerhaavia diffusa using cold restraint stress model. Int $\mathrm{J}$ Pharm Pharm Sci 2001;3:130-2.

12. Ashwini S, Babut VS, Saritha, Shantaram M. Seaweed extracts exhibit anticancer activity against hela cell lines. Int J Curr Pharm Res 2017;9:114-7. 